\title{
Effectiveness and early postoperative outcomes of palliative endoluminal stenting versus Hartmann's procedure in acute malignant bowel obstruction in high-risk patients
}

\author{
Mohammed Fayek Mahfouz ${ }^{1}$, Tamer M. Saeid Salama ${ }^{1}$, Amr H. Afifi ${ }^{1}$, Hany Mansour Khalil Dabous ${ }^{2}$ \\ Departments of ${ }^{1}$ General Surgery and ${ }^{2}$ Hepatology and Gastroenterology, Faculty of Medicine, Ain Shams University, Cairo, Egypt
}

Purpose: The emergency intervention for acute malignant left-sided colonic obstruction remains controversial. Conflicting reports exist regarding the efficacy and safety of endoscopic placement of self-expandable metallic stents (SEMS) vs. primary surgery. Most reports focus on SEMS insertion as a bridge to surgery.

Methods: An observational nonrandomized study at a single center in Cairo, Egypt included 65 high-risk patients (American Society of Anesthesiologists physical status classification $\geq$ III, age $>60$ years) with acute malignant metastatic (stage IV) colonic obstruction. Twenty-nine patients underwent primary surgery (Hartmann's procedure, HP), and 35 patients underwent SEMS insertion.

Results: All cases that underwent SEMS insertion were technically successful. The 2 procedures were comparable in clinical success rates but a statistically significant difference existed between them regarding the duration of postoperative hospital stay in the HP and SEMS group $(7.7 \pm 3.1$ days vs. $3.5 \pm 0.6$ days, retrospectively; $\mathrm{P}<0.001)$, the interval before regaining oral feeding $(41.8 \pm 26.8$ hours vs. $27.6 \pm 18.5$ hours, retrospectively; $\mathrm{P}=0.015)$, and the duration of intensive care unit (ICU) admission (5.0 \pm 1.7 days vs. $1.5 \pm 0.7$ days, retrospectively; $\mathrm{P}=0.035)$. Six patients $(20.7 \%)$ in the HP group and 2 patients (5.7\%) in the SEMS group required postoperative ICU admission.

Conclusion: SEMS placement provides comparable efficacy and safety to HP in managing acute malignant obstruction of the rectosigmoid region in high-risk individuals, with faster recovery and less hospital and ICU admission time.

Keywords: Endoscopic stenting; Hartmann’s procedure; Colonic obstruction; Colorectal neoplasms

\section{INTRODUCTION}

It is estimated that between $7 \%$ and $47 \%$ of colorectal cancer cases present with incomplete or complete bowel obstruction $[1,2]$. This represents a clinical and surgical challenge since it often occurs in old, frail patients (high risk from a surgical standpoint) and is indicative of advanced malignancy [3]. Moreover, bowel

Received: Nov 22, 2020 - Revised: Jan 24, 2021 - Accepted: Jan 28, 2021 Correspondence to: Mohammed Fayek Mahfouz, M.D.

Department of General Surgery, Faculty of Medicine Ain Shams University, Ramses Street, Abbassia, Cairo 11517, Egypt

Tel: +20-1551250140

E-mail:drmohamedelnhas@gmail.com

ORCID: https://orcid.org/0000-0001-6364-6632

(C) 2022 The Korean Society of Coloproctology

This is an open-access article distributed under the terms of the Creative Commons Attribution NonCommercial License (https://creativecommons.org/licenses/by-nc/4.0) which permits unrestricted noncommercial use, distribution, and reproduction in any medium, provided the original work is properly cited. obstruction is a poor prognostic indicator that is associated with less overall survival [4]. Emergency surgical intervention in these patients actually carries a significant risk of mortality and morbidity, with a high rate of complications in comparison to elective surgery including anastomosis dehiscence, venous thrombosis, and infection $[5,6]$.

The emergency intervention for acute malignant left-sided colonic obstruction has, thus, been a controversial topic. For a long time, primary resection has been considered the gold-standard surgical option by most surgeons [6]. Primary resection options include a one-stage resection, or a staged resection with end colostomy (Hartmann's procedure, HP). The latter has been deemed the safer option since it circumvents the need for risky anastomosis creation in an emergency setting [7]. This is especially true in highrisk patients including those of advanced age, and worse Dukes' stage (currently replaced by TNM staging) and American Society of Anesthesiologists (ASA) physical status (PS) classification [8]. 
The use of self-expandable metal stent (SEMS) via endoscopic placement has been advocated as a simpler and safer means to relieve acute malignant colonic obstruction, mainly with rectosigmoid malignant lesions [5]. In such cases, the SEMS may act either as a palliative option or as a bridge to surgery (deferring the time of resection surgery to a later, more controlled elective setting), although the distinction between both during the emergency presentation is rather artificial and the final decision is made after the patient's recovery from the obstruction [6].

A multitude of reports with variable results have attempted to assess the effectiveness of SEMS in managing acute malignant colonic obstruction [1, 2, 5, 9-11]. Most reports have proven SEMS to be at least non-inferior to primary resection, with some even reporting more favorable outcomes with SEMS when it came to short-term survival. Moreover, the use of SEMS has been associated with shorter hospital stays and less required procedures, which has further promoted their usage being cost-effective [12]. However, the procedure is not without its possible complications and the major ones are bleeding, perforation, and stent migration [4]. The main limitations for SEMS usage include availability and a steep learning curve for endoscopic placement [10].

In this work, we report our experience with palliative endoluminal stenting vs. HP in managing acute left-sided malignant metastatic colonic obstruction in high-risk patients with regards to technical and clinical success, and early (30 days) postoperative outcomes.

\section{METHODS}

This observational nonrandomized study was conducted over a period of 18 months (June 2018-December 2019) at Ain Shams University Hospital in Cairo, Egypt. The study adhered to the tenets of the Declaration of Helsinki. Ethical approval from Ain Shams University Hospitals Ethics Committee (No. FWA 000017585) was obtained and written informed consent from all patients was included.

Patients were included in the study if they presented to the accidents and emergency (A \& E) department with an acute malignant metastatic colonic obstruction within 72 hours. Patients assessed to have complete bowel obstruction due to advanced cancer colon (stage IV of TNM staging, assessed by radiological means) and who were high risk (age, $>60$ years; ASA PS grade, $\geq$ III) were eligible for the study. Exclusion criteria were partial or reversible bowel obstruction (responsive to medical treatment), patients who proved to have different or multiple causes of obstruction, those who later proved to have a benign tumor or an early stage (I-III) cancer, those who had previous colonic surgery or had received neoadjuvant chemotherapy, or those with sepsis at the time of presentation.

All patients underwent a complete physical examination at the A \& E department that included bimanual pelvic and rectal palpation. Upright abdominal X-ray filming and pelvi-abdominal computed tomography scanning (with intravenous contrast when the patient's condition allowed) were carried out to confirm the diagnosis of bowel obstruction and identify the malignant etiology. Radiological evidence was the base for preoperative malignant diagnosis and staging owing to the acute presentation, and tissue biopsy acquisition for histological confirmation was postponed to the intraoperative setting rather than preoperatively. All patients received the standard medical care for bowel obstruction. Patients were then prepared for either HP or an endoscopic stenting procedure. The choice of the procedure was multifactorial based on the evaluation of a multidisciplinary team including the general surgeon, the radiologist, the oncologist, the anesthesiologist, and the gastroenterologist, and based on the availability of SEMS and adequately skilled personnel for its endoscopic placement (convenience stratification).

Regarding the SEMS, the procedure was performed under sedation and analgesia with fluoroscopic guidance. We used the WallFlex Colonic Stent (Boston Scientific, Marlborough, MA, USA) that had an uncovered nitinol length of 9 to $12 \mathrm{~cm}$ and a diameter of 25 to $30 \mathrm{~mm}$. A stiff guidewire was introduced through the catheter then the catheter was removed. The SEMS was then advanced over the stiff wire to be at least $2 \mathrm{~cm}$ proximal and $2 \mathrm{~cm}$ distal to the stricture that had been identified by contrast enema. After assuring proper positioning, the SEMS was released, and accurate positioning defined technical success.

The main short-term (30 days) outcomes measured were clinical success (the passage of feces through the colostomy in cases with HP, or defecation in cases with SEMS within 48 hours), procedure-related complication rates (according to the ClavienDindo classification system [13]), intensive care unit (ICU) admission, hospital stay, and cancer-specific mortality rate.

Data were revised, coded, entered on a computer, and analyzed using IBM SPSS Statistics ver. 20.0 (IBM Corp., Armonk, NY, USA). Independent-samples t-test of significance was used when comparing between 2 means. A chi-square test of significance was used to compare proportions between 2 qualitative parameters. The confidence interval was set to $95 \%$ and the margin of error accepted was set to $5 \%$, so the P-value was considered significant if less than 0.05 .

\section{RESULTS}

The total number of patients recruited for the study was $64 ; 47$ males (73.4\%) and 17 females (26.6\%). The range of the patients' age was 61 to 79 years. Twenty-nine patients (45.3\%) underwent $\mathrm{HP}$ while 35 patients (54.7\%) underwent endoscopic SEMS insertion. Table 1 shows the major demographic and clinical characteristics of each group. Most of the patients $(\mathrm{n}=58,90.6 \%)$ had an ASA PS grade of III, while a minority $(n=6,9.4 \%)$ had an ASA PS grade of IV, and none had a higher ASA PS grade. Most patients had the malignant lesion located in the sigmoid colon $(\mathrm{n}=60,93.8 \%)$, a small percentage $(\mathrm{n}=4,6.2 \%)$ had the lesion in 
Table 1. Major demographic and clinical characteristics of HP and SEMS groups $(n=64)$

\begin{tabular}{lccc}
\hline Variable & HP group & SEMS group & P-value \\
\hline No. of patients & 29 & 35 & \\
Age (yr) & $67.2 \pm 4.9(61-75)$ & $69.0 \pm 5.4(63-79)$ & 0.171 \\
Sex & & & 0.866 \\
$\quad$ Male & $21(72.4)$ & $26(74.3)$ & \\
$\quad$ Female & $8(27.6)$ & $9(25.7)$ & \\
ASA PS classification & & & 0.270 \\
III & $25(86.2)$ & $33(94.3)$ & \\
IV & $4(13.8)$ & $2(5.7)$ & \\
Site of lesion & & & 0.218 \\
Sigmoid & $26(89.7)$ & $34(97.1)$ & \\
Rectum & $3(10.3)$ & $1(2.9)$ & \\
Clinical presentation & & & \\
Nausea & $29(100)$ & $34(97.1)$ & \\
Vomiting & $21(72.4)$ & $26(74.3)$ & \\
Abdominal pain & $25(86.2)$ & $29(82.9)$ & \\
Constipation & $7(24.1)$ & $15(42.9)$ &
\end{tabular}

Values are presented as number only, mean \pm standard deviation (range), or number (\%).

HP, Hartmann's procedure; SEMS, self-expandable metal stent; ASA, American Society of Anesthesiologists; PS, physical status.

the rectum, and none had the lesion in the descending colon. The main presenting symptoms were nausea (98.4\%), abdominal pain (84.4\%), vomiting (73.4\%), and constipation (34.4\%). There were no statistically significant differences among the HP and SEMS group regarding all recorded demographic and clinical characteristics.

All cases that underwent SEMS insertion were technically successful. Only 1 case (2.9\%) required a second stent insertion due to stent obstruction that occurred 9 days following the initial procedure. Table 2 demonstrates the major early clinical outcomes in each group. Two patients (6.9\%) in the HP group and 1 case (2.9\%) in the SEMS group did not achieve clinical success; the difference was not statistically significant. A statistically significant difference, however, existed between both groups regarding the duration of postoperative hospital stay $(7.7 \pm 3.1$ days in the HP group and $3.5 \pm 0.6$ days in the SEMS group, $\mathrm{P}<0.001)$, the interval between the procedure and regaining of oral feeding $(41.8 \pm 26.8$ hours in the HP group and $27.6 \pm 18.5$ hours in the SEMS group, $\mathrm{P}=0.015$ ), and the duration of ICU admission (5.0 \pm 1.7 days in the HP group and $1.5 \pm 0.7$ days in the SEMS group, $\mathrm{P}=0.035$ ). Six patients (20.7\%) in the HP group and 2 patients (5.7\%) in the SEMS group required postoperative ICU admission, this was majorly related to their preoperative ASA PS classification.

Regarding procedure-related complications, 23 patients (79.3\%) in the HP group and 28 patients (80.0\%) in the SEMS group did
Table 2. Early (30 days) postoperative outcomes of HP and SEMS groups $(\mathrm{n}=64)$

\begin{tabular}{lccc}
\hline Variable & $\begin{array}{c}\text { HP group } \\
(\mathrm{n}=29)\end{array}$ & $\begin{array}{c}\text { SEMS group } \\
(\mathrm{n}=35)\end{array}$ & P-value \\
\hline Clinical success $^{\mathrm{a}}$ & & & 0.579 \\
$\quad$ Yes & $27(93.1)$ & $34(97.1)$ & \\
$\quad$ No & $2(6.9)$ & $1(2.9)$ & \\
$\begin{array}{l}\text { Regaining oral feeding } \\
\text { (hr) }\end{array}$ & $41.8 \pm 26.8(18-108)$ & $27.6 \pm 18.5(6-72)$ & $0.015^{\star}$ \\
Postoperative hospital & $7.7 \pm 3.1(5-17)$ & $3.5 \pm 0.6(3-5)$ & $<0.001^{*}$ \\
stay (day) & & & \\
ICU admission (day) & $5.0 \pm 1.7(2-7)$ & $1.5 \pm 0.7(1-3)$ & $0.035^{*}$ \\
$\quad$ No & $23(79.3)$ & $33(94.3)$ & 0.071 \\
Yes & $6(20.7)$ & $2(5.7)$ & \\
Complication ${ }^{\mathrm{b}}$ & & & \\
None & $23(79.3)$ & $28(80.0)$ & 0.944 \\
Grade I-II & $4(13.8)$ & $4(11.4)$ & \\
Grade III-V & $2(6.9)$ & $3(8.6)$ & \\
\hline
\end{tabular}

Values are presented as number (\%) or mean \pm standard deviation (range). HP, Hartmann's procedure; SEMS, self-expandable metal stent; ICU, intensive care unit.

aProduction of feces within 48 hours of the procedure without recurrence of the obstruction within the 30-day follow-up. ${ }^{b}$ Clavien-Dindo classification system.

${ }^{*}$ Statistically significant $(P<0.05)$.

not have procedure-related complications. Four patients (13.8\%) in the HP group and 4 patients (11.4\%) in the SEMS group had a grade I to II Clavien-Dindo complication including wound infection, paralytic ileus, or self-limited rectal bleeding. For grade III or higher Clavien-Dindo complications, 2 patients (6.9\%) in the HP group were affected with rectal stump leak that required surgical revision, while 3 patients (8.6\%) in the SEMS group were affected with stent migration, complicating in 1 of them with bowel perforation that required surgical intervention. The difference in complication rates between both groups was not statistically significant $(\mathrm{P}=0.944)$. There were neither procedure-related mortalities nor cancer-specific mortality in both groups over the early (30day) recovery period.

\section{DISCUSSION}

In this work, we demonstrated that both HP and endoscopic SEMS insertion had comparable efficacy in relieving acute malignant bowel obstruction in high-risk patients, but SEMS insertion was associated with faster recovery and shorter postoperative stay and ICU admission time (if required).

Most studies reporting on SEMS insertion utilize stenting as a bridge to surgery that is usually carried out within days or weeks of the original procedure $[1,2,5]$, and in that manner do not capture longer outcome measurement for SEMS insertion on its own 
(palliative stenting). The Royal College of Surgeons in England recommends the usage of SEMS only when primary surgery is not feasible, as a bridge to surgery, or as a palliative measure in patients' situations where surgery would be unethical [6]. This is stemming from the fact that not enough robust data exist about SEMS usage, and with some reports even warning about significant complication rates in patients who underwent the procedure $[14,15]$, primary surgery remains the preferred option by most surgeons [6]. On the other hand, multiple studies have reported SEMS insertion to be non-inferior and equally safe to primary surgery $[9,16]$, with better cost-effectiveness achieved through earlier recovery and shorter inpatient and ICU stays [12]. This was true in our experience where major complication rates were comparable in both groups, no mortality was encountered in either group, but more ICU admissions and longer hospital stays were seen in the HP group.

The problem of ICU beds scarcity is more pronounced in developing nations, and policies are in place to triage those patients with sudden clinical deterioration to determine the ones in most need of available beds $[17,18]$. Consequently, developing nations would benefit most from interventions that reduce ICU admission requirements and hospital stay costs. This has proven to be the case with SEMS usage in malignant colonic obstruction in both our experience and other reported experiences $[2,12]$.

Nevertheless, the debate continues over the optimum treatment option for patients with acute left-sided colonic obstruction [19]. Multiple review articles $[4,10,20]$ have attempted to summarize the results of various studies in the literature concerned with SEMS, but owing to different study designs, different make of stents used, variable patient demographics and clinical characteristics, and variable outcomes reported, no definite practice recommendations are provided to date. In a Cochrane Systematic Review published in 2011, Sagar [21] reviewed the published randomized controlled trials evaluating SEMS vs. primary surgery. Five trials were identified with a sum of 207 subjects. Although the analysis showed that SEMS provided shorter operative and recovery time, and comparable complication and 30-day mortality rates, a higher clinical success rate was reported in the primary surgery group. A more recent systematic review and meta-analysis by Veld et al. [22] included 18 studies with a sum of 1,518 subjects and exclusively focused on the early postoperative period. The authors concluded that SEMS was superior to primary surgery in the palliative setting mainly due to lower complication rates and faster recovery.

Bowel perforation is the most serious complication of endoscopic SEMS insertion with a reported mortality rate of $16 \%$ [23]. Most perforations occur in the 30 days postoperative, and the complication occurs with a pooled rate of $4.9 \%$ across reported studies [24]. In our cohort of patients, only 1 patient (2.9\%) had a bowel perforation that was successfully managed surgically. Another important complication is stent migration that can be of early- or late-onset and occurs at an average rate of $2.1 \%$ [21], but with reported rates as high as $22 \%$ [14]. In our SEMS group, $8.6 \%$ of the subjects had stent migration which is within the acceptable range. Another limitation of the stenting procedure is the difficult technical aspect. In a pooled analysis, technical and clinical success rates were $86 \%$ and $91 \%$, respectively [21]. In our experience, technical success was $100 \%$ while clinical success was $97.1 \%$ in the SEMS group. It seems that with cumulative experience, higher technical success rates would be achievable [2]. A final concern would be stent-induced tumor migration [14] but would not be expectedly observed in the short-term postoperatively.

The strength of our study is its focus on specific SEMS usage (palliative care) in a specific set of patients (high-risk, obstructed stage IV colorectal cancer patients) in comparison to a specific surgical procedure (HP) with focus on early outcomes (30 days postoperative). An important limitation to the work is the nonrandomized, nonblinded design of the study that could be a source of allocation and selection bias, respectively. Another limitation is the relatively small sample size and the single-center experience. Finally, outcomes of both surgical interventions and endoscopic SEMS placement are affected by the technical skills of the surgeon/operator.

In conclusion, endoscopic SEMS placement provides comparable efficacy and safety to primary surgery (HP) in managing acute malignant obstruction of the rectosigmoid region in high-risk individuals. SEMS placement, although not free of its possible major complications, seems to provide faster recovery with less hospital and ICU admission time, and should be favorable whenever technical expertise is available, especially in resource-limited healthcare settings.

\section{CONFLICT OF INTEREST}

No potential conflict of interest relevant to this article was reported.

\section{FUNDING}

None.

\section{REFERENCES}

1. Consolo $\mathrm{P}$, Giacobbe G, Cintolo M, Tortora A, Famà F, Gioffrè Florio $\mathrm{M}$, et al. Colonic acute malignant obstructions: effectiveness of self-expanding metallic stent as bridge to surgery. Turk J Gastroenterol 2017;28:40-5.

2. van Silfhout L, Smeekens EA, van Eekeren RR, Burger JP. Outcomes of stenting as a bridge to surgery in malignant colonic obstruction, with emphasis on perforation rate and clinical success. Surg Laparosc Endosc Percutan Tech 2020;30:332-8.

3. Winner M, Mooney SJ, Hershman DL, Feingold DL, Allendorf JD, Wright JD, et al. Incidence and predictors of bowel obstruction in elderly patients with stage IV colon cancer: a population- 
based cohort study. JAMA Surg 2013;148:715-22.

4. Gainant A. Emergency management of acute colonic cancer obstruction. J Visc Surg 2012;149:e3-10.

5. Occhionorelli S, Tartarini D, Cappellari L, Stano R, Vasquez G. Colonic stent placement as a bridge to surgery in patients with left-sided malignant large bowel obstruction. An observational study. G Chir 2014;35:283-9.

6. Trompetas V. Emergency management of malignant acute leftsided colonic obstruction. Ann R Coll Surg Engl 2008;90:181-6.

7. Meyer F, Marusch F, Koch A, Meyer L, Führer S, Köckerling F, et al. Emergency operation in carcinomas of the left colon: value of Hartmann's procedure. Tech Coloproctol 2004;8 Suppl 1:s226-9.

8. Tekkis PP, Kinsman R, Thompson MR, Stamatakis JD; Association of Coloproctology of Great Britain, Ireland. The Association of Coloproctology of Great Britain and Ireland study of large bowel obstruction caused by colorectal cancer. Ann Surg 2004; 240:76-81.

9. García-Cano J. Colorectal stenting as first-line treatment in acute colonic obstruction. World J Gastrointest Endosc 2013;5:495-501.

10. Lim TZ, Tan KK. Endoscopic stenting in colorectal cancer. J Gastrointest Oncol 2019;10:1171-82.

11. Arezzo A, Balague C, Targarona E, Borghi F, Giraudo G, Ghezzo L, et al. Colonic stenting as a bridge to surgery versus emergency surgery for malignant colonic obstruction: results of a multicentre randomized controlled trial (ESCO trial). Surg Endosc 2017; 31:3297-305.

12. Singh H, Latosinsky S, Spiegel BM, Targownik LE. The cost-effectiveness of colonic stenting as a bridge to curative surgery in patients with acute left-sided malignant colonic obstruction: a Canadian perspective. Can J Gastroenterol 2006;20:779-85.

13. Dindo D, Demartines N, Clavien PA. Classification of surgical complications: a new proposal with evaluation in a cohort of 6336 patients and results of a survey. Ann Surg 2004;240:205-13.

14. Fernández-Esparrach G, Bordas JM, Giráldez MD, Ginès A, Pellisé $\mathrm{M}$, Sendino $\mathrm{O}$, et al. Severe complications limit long-term clinical success of self-expanding metal stents in patients with obstructive colorectal cancer. Am J Gastroenterol 2010;105:1087-
93.

15. Small AJ, Coelho-Prabhu N, Baron TH. Endoscopic placement of self-expandable metal stents for malignant colonic obstruction: long-term outcomes and complication factors. Gastrointest Endosc 2010;71:560-72.

16. Kim H, Kim SH, Choi SY, Lee KH, Won JY, Lee DY, et al. Fluoroscopically guided placement of self-expandable metallic stents and stent-grafts in the treatment of acute malignant colorectal obstruction. J Vasc Interv Radiol 2008;19:1709-16.

17. Stelfox HT, Hemmelgarn BR, Bagshaw SM, Gao S, Doig CJ, Nijssen-Jordan $\mathrm{C}$, et al. Intensive care unit bed availability and outcomes for hospitalized patients with sudden clinical deterioration. Arch Intern Med 2012;172:467-74.

18. Sinuff T, Kahnamoui K, Cook DJ, Luce JM, Levy MM; Values Ethics and Rationing in Critical Care Task Force. Rationing critical care beds: a systematic review. Crit Care Med 2004;32:158897.

19. Grundmann RT. Primary colon resection or Hartmann's procedure in malignant left-sided large bowel obstruction? The use of stents as a bridge to surgery. World J Gastrointest Surg 2013;5:1-4.

20. Baron TH, Wong Kee Song LM, Repici A. Role of self-expandable stents for patients with colon cancer (with videos). Gastrointest Endosc 2012;75:653-62.

21. Sagar J. Colorectal stents for the management of malignant colonic obstructions. Cochrane Database Syst Rev 2011;2011: CD007378.

22. Veld J, Umans D, van Halsema E, Amelung F, Fernandes D, Lee MS, et al. Self-expandable metal stent (SEMS) placement or emergency surgery as palliative treatment for obstructive colorectal cancer: a systematic review and meta-analysis. Crit Rev Oncol Hematol 2020;155:103110.

23. Seo SY, Kim SW. Endoscopic management of malignant colonic obstruction. Clin Endosc 2020;53:9-17.

24. Datye A, Hersh J. Colonic perforation after stent placement for malignant colorectal obstruction--causes and contributing factors. Minim Invasive Ther Allied Technol 2011;20:133-40. 